\title{
Procesos de Urbanización Popular y Derecho a la Ciudad en el Oriente de la Zona Metropolitana del Valle de México
}

\author{
Processes of Popular Urbanization and Right to the City in the \\ East of the Metropolitan Area of the Valley of Mexico
}

\section{Processos de UUrbanização Popular e Direito à Cidade no Leste da Area Metropolitana do Vale do México} Rubén Marcelo Castillo Álvarez
Lic. en Diseño de los Asentamientos Humanos, Doctor en Geografía
Universidad Autónoma Metropolitana, Xochimilco, México. ruben900@hotmail.com

(iD) https://orcid.org/0000-0002-0834-3820
Recibido: septiembre 6 de 2021

Aceptado: noviembre 4 de 2021

Publicado: noviembre 10 de 2021

\section{RESUMEN}

El objetivo es analizar el proceso de urbanización popular, sus formas de gestión territorial y las prácticas sociales encaminadas a refrendar el derecho a la ciudad. Se examinan dos casos: el primero sobre colonias populares y el segundo en una comunidad indígena triqui, ambas experiencias localizadas en el oriente de la Zona Metropolitana del Valle de México. La metodología empleada es con base en el análisis documental de dos investigaciones que tratan de los procesos urbanos populares. Se concluye que, debido a la escasa intervención urbana del Estado, los pobladores crean sus propias prácticas sociales en busca de alcanzar el derecho a la ciudad.

Palabras clave: Derecho a la ciudad; movimiento urbano popular; pobladores; procesos de urbanización popular.

\section{ABSTRACT}

The objective is to analyze the popular urbanization process, its forms of territorial management and the social practices aimed at endorsing the right to the city. Two cases are examined: the first on popular colonies and the second in a Triqui indigenous community, both experiences located in the eastern Metropolitan Area of the Valley of Mexico. The methodology used is based on the documentary analysis of two investigations that deal with popular urban processes. It is concluded that, due to the scarce urban intervention of the State, the inhabitants create their own social practices in search of achieving the right to the city.

Keywords: Right to the city; popular urban movement; settlers; popular urbanization processes. 


\section{RESUMO}

O objetivo é analisar o processo de urbanização popular, suas formas de gestão territorial e as práticas sociais voltadas para a efetivação do direito à cidade. Dois casos são examinados: o primeiro em colônias populares e o segundo em uma comunidade indígena Triqui, ambas experiências localizadas na Região Metropolitana oriental do Vale do México. A metodologia utilizada baseia-se na análise documental de duas investigações que tratam de processos urbanos populares. Conclui-se que, devido à escassa intervenção urbana do Estado, os moradores criam suas próprias práticas sociais em busca da conquista do direito à cidade.

Palavras-chave: Direito à cidade; movimento popular urbano; colonos; processos de urbanização popular.

\section{INTRODUCCIÓN}

Las ciudades donde el proceso de urbanización es intenso, ha traído consigo varias problemáticas sociales, económicas y territoriales. Una es la concentración geográfica desproporcionada de la población urbana. En el caso de América Latina, se advierte que el $81 \%$ de la población vive actualmente en áreas urbanas (CEPAL, 2018). Simultáneamente, se observan procesos de urbanización intensos y caóticos como en las ciudades de Buenos Aires, Argentina, y Medellín, Colombia (Mendoza, 2016, p. 56).

En Medellín, estos procesos figuran por una urbanización desmedida con un déficit de vivienda adecuada, que en su construcción se caracteriza por la improvisación en su construcción, localizada en zonas de alto riesgo, así como la desarticulación e improvisación de las acciones gubernamentales, falta de legalización y regularización de predios y viviendas (Palmett, 2016, pp. 42-43).

Otra problemática se refiere concretamente a los actores sociales que participan en su construcción y conformación, como la población con recursos escasos, que es la principal protagonista de la urbanización con un matiz popular (Quiroz y Alcántar, 2017).

Entonces, se habla más apropiadamente de un proceso de urbanización popular, lo que da cuenta de la importancia del tema que aquí se trata. De acuerdo con Quiroz y Alcántar (2017, p. 48), en México, "... los barrios de origen irregular, construidos de forma progresiva mediante la participación directa de sus propios habitantes, representan más del $50 \%$ de las áreas urbanizadas actuales".

En el caso de la Zona Metropolitana del Valle de México $^{1}$ (ZMVM), el 54\% de la superficie urbanizada corresponde a colonias populares de origen informal (Garza en Quiroz y Alcántar, 2017, p. 48). Por ejemplo, es el caso de los asentamientos humanos en las alcaldías y municipios del oriente de la Zona Metropolitana del Valle de México (OZMVM).

Es en las colonias populares o asentamientos humanos populares en los cuales, durante las últimas décadas, creció de forma contundente la población en los territorios con urbanización popular de manera informal, con la subsiguiente precarización de la calidad de vida de sus pobladores: "... Es una "urbanización" sin infraestructuras ni servicios; es "urbanización precaria" (Pírez, 2013, p. 49).

La delimitación territorial del OZMVM, es una propuesta realizada por el autor (consultar la Figura 1), con base en Mora (2014, p. 44). Este autor incluye a los municipios de Nezahualcóyotl, Chimalhuacán, La Paz, Chicoloapan, Ixtapaluca y Valle de Chalco del Estado de México. Asimismo, también se consideró la propuesta de Almaguer y Landín (2018) quienes incluyen a las alcaldías de Iztapalapa, Tláhuac e Iztacalco como parte

\footnotetext{
1. La cual se compone por 59 municipios del Estado de México y 16 alcaldías de la Ciudad de México. Fuente: Delimitación de zonas metropolitanas de México 2015, Consejo Nacional de Población, México.
} 
del oriente de la Ciudad de México, así como a los municipios de Nezahualcóyotl, La Paz, Ixtapaluca, Valle de Chalco y Chalco del oriente del Estado de México.

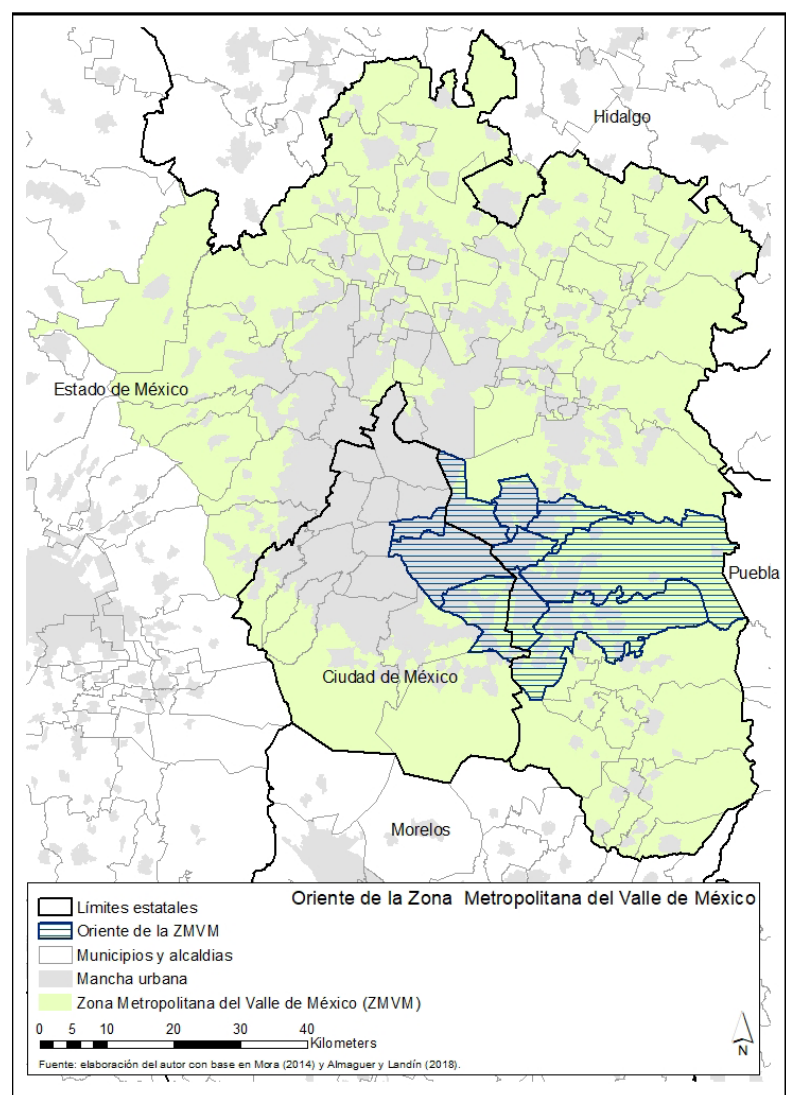

Figura 1. Oriente de la Zona Metropolitana del Valle de México.

Fuente: elaboración del autor con base en Mora (2014) y Almaguer y Landín (2018).

En el proceso de urbanización popular, las circunstancias económicas y sociales de las comunidades urbanas declina en la actualidad. Por ejemplo, se estima que en la Zona Metropolitana del Valle de México la población trabajadora que pernocta en las zonas habitacionales populares localizadas lejos de los centros laborales realiza viajes para ir al trabajo de hasta 2 horas tan solo de ida (INEGI, 2017). Entre otros aspectos, esta situación deteriora la calidad de vida de la población de estas comunidades. Consecuentemente, estas poblaciones de escasos recursos se encuentran territorialmente desfavorecidas y con profundas dificultades económicas para acceder a otros espacios de la ciudad.
Por lo tanto, es desde el espacio local e inmediato, como el de la vivienda, que las comunidades populares se adecuan al territorio, se apropian de este y lo autogestionan - como un derecho-, hasta otras escalas territoriales como la calle, el barrio, la colonia, el pueblo y la ciudad, y conforme se incrementa la escala, dicho derecho se diluye gradualmente.

Entonces, aparece el término de derecho a la ciudad que fue acuñado inicialmente por Henri Lefebvre en la década de 1960. El autor lo definió como "el derecho de los habitantes urbanos a construir, decidir y crear la ciudad, y hacer de ésta un espacio privilegiado de lucha anticapitalista" (Lefebvre en Molano, 2016, p. 4). Entonces, el derecho a la ciudad de la población de recursos escasos es exiguo en comparación con otras clases sociales como la media o la alta. Además, estas comunidades tienen poca accesibilidad urbana hacia otras zonas o colonias de clase media de la Zona Metropolitana del Valle de México. ${ }^{2}$

Empero, las poblaciones con escasos recursos delinean unas estrategias sociales, económicas y territoriales en las que se replantean las formas de acceso a la ciudad y al propio derecho urbano del que debieran gozar. Esto, ante una aparente segregación urbana del que son objeto por las practicas mercantilistas que realizan los diversos actores de la sociedad y de la ciudad. De esta manera, la población urbana de las colonias populares crea y recrea unas formas de organización urbana sui generis que le caracterizan y se manifiestan en el propio territorio desde el ámbito local.

Una vez que los actores salen de su vivienda cotidiana, enfrentan obstáculos y fricciones que limitan su acceso a los diversos segmentos de la ciudad no-popular. Por lo demás, se advierten comportamientos de resistencia social con expresiones sociales, artísticas y culturales como formas de apropiación urbana popular, incluso, alcanzando rasgos arquitectónicos y urbanos de los contextos territoriales populares, es decir, en los barrios y colonias o pueblos tradicionales.

2. Como las colonias y fraccionamientos de clase media del poniente y sur de la Ciudad de México, entre otras. 
El objetivo principal del trabajo es analizar el proceso de urbanización popular, las interacciones y las formas de gestión urbana, construidas por los actores urbanos, con el propósito de identificar las prácticas sociales y urbanas encaminadas a refrendar el derecho a la ciudad.

La hipótesis plantea que los procesos de urbanización popular lo realizan actores diversos, con interacciones y formas de gestión originales y son el componente básico para encontrar el derecho a la ciudad. La pregunta de investigación es ¿cómo logran los pobladores urbanos resolver sus necesidades cotidianas en relación con la vivienda, el equipamiento urbano y los servicios básicos, para alcanzar el derecho a la ciudad?

\section{METODOLOGÍA}

La metodología empleada es con base en la investigación documental de dos estudios que han aportado de forma original al tema de los procesos que se generan en el crecimiento urbano en colonias populares del oriente de la Zona Metropolitana del Valle de México. El primer trabajo es una tesis de doctorado que se aproxima a explicar la urbanización en 14 colonias populares asentadas en el municipio de La Paz en el Estado de México; y el segundo es un artículo de investigación que explica la experiencia de gestión urbana para la producción y apropiación del espacio urbano público, por parte de una organización social conformada por población con origen indígena triqui, localizada en la alcaldía Iztapalapa en la Ciudad de México.

\section{Antecedentes de la Urbanización Popular: el Movimiento Urbano Popular.}

Con base en Quiroz y Alcántar (2017, pp. 55-56), el proceso de urbanización popular comprende las siguientes etapas: 1) El periodo revolucionario (1910-1921), 2) Un periodo de experimentación social (posrevolucionario) en las décadas de 1920 y 1930,3$)$ Una etapa de crecimiento económico y urbanización acelerada (1945-1980), y 4) Crisis y proyecto neoliberal (1990-2015).
En la Ciudad de México, en el tercer y cuarto periodos, aparecen algunos asentamientos populares emblemáticos y organizaciones sociales como: la Unión Popular Revolucionaria Emiliano Zapata, los vecinos organizados de El Molino, el Campamento 2 de octubre, la Cooperativa Palo Alto, el Pedregal de Santo Domingo, San Miguel Teotongo (Quiroz y Alcántar, 2017, pp. 52-55), la Asamblea de Barrios, el Frente Popular Francisco Villa, La Unión de Vecinos 19 de septiembre -este último se conformó por trabajadores y trabajadoras maquileros en su mayoría afectados en sus viviendas por el sismo de 1985 en la Ciudad de México.

El desarrollo de la urbanización popular como forma de producción del espacio urbano es significativo: se calcula que el $31 \%$ del área urbana de la Ciudad de México, con alrededor del $44.5 \%$ de su población habitaba en urbanizaciones populares (Connolly en Gutiérrez, 2016, p. 7). Una fase importante del proceso se encuentra en la movilización social y la organización política para la gestión y autogestión del proceso urbano popular, con la aparición a fines de la década de los 60 del Movimiento Urbano Popular (MUP).

El MUP se presentó en otras ciudades del país, como: Chihuahua, Monterrey, Durango; y en otros estados como Puebla, Nayarit, Estado de México, entre otros. Finalmente, se conformó en la década de 1980 una Coordinación Nacional del Movimiento Urbano Popular (CONAMUP) (Gutiérrez, 2016, p. 92).

El MUP, desde entonces, ha mediado y contribuido a delinear la forma y la estructura que adquirió el espacio urbano en la Ciudad de México, principalmente en el tipo de poblamiento denominado "colonias populares" (Connolly en Gutiérrez, 2016, p. 7), espacios que fueron resultado de los múltiples procesos de urbanización popular que se desarrollaron en los frentes de crecimiento de la ciudad (Gutiérrez, 2016). 
Como señala Gutiérrez, (2016):

Si bien el movimiento urbano popular en la Ciudad de México no fue el principal agente que realizó procesos de apropiación de tierras para su urbanización y construcción del espacio habitacional de los sectores populares de la ciudad, este movimiento social contribuyó decisivamente en la determinación de la forma y estructura que adquiriría el espacio urbano donde desarrollo sus prácticas organizativas (Gutiérrez, 2016, p. 7).

En los asentamientos irregulares o en las colonias populares, es decir, en las zonas con ausencia de trámites legales en la adquisición del suelo, localizados en zonas de riesgo por inundaciones o deslizamientos de tierra, viviendas con limitado acceso a los servicios; se perciben acciones por mejorar las condiciones de habitabilidad de sus pobladores, Gutiérrez (2016) agrega:

...la organización y movilización social para evitar los desalojos y el asesoramiento de los colonos urbanos y sus familias en el proceso de regularización y escrituración de los predios que mantenían en posesión, fueron algunas de las acciones más importantes que el movimiento urbano popular realizó, para contribuir en la configuración del espacio urbano en la Ciudad de México (Gutiérrez, 2016, p.7).

Otra gran parte de los procesos de urbanización popular en la Ciudad de México, se han desarrollado bajo la tutela de actores políticos identificados $\mathrm{y} / \mathrm{o}$ dependientes al Estado, principalmente al Partido Revolucionario Estatal (PRI). De forma reciente, como el Partido de la Revolución Democrática (PRD) y los líderes identificados con dichos partidos $u$ organizaciones gremiales como la Confederación Nacional de Organizaciones Populares (CNOP), la Confederación de Trabajadores de México (CTM), y de agrupaciones políticas como Antorcha Campesina, entre muchas otras.

De acuerdo con Gutiérrez (2016), existieron procesos de organización política y movilización social en las colonias populares, que, aunque no se desarrollaron de forma autónoma al Estado, sí permitieron a los colonos urbanos realizar la dirección del proceso de gestión y producción del espacio urbano. Las organizaciones de colonos pudieron desarrollar una política y práctica organizativa independiente del Estado y del partido que monopolizaba hegemónicamente las instituciones estatales (Núñez y Farrera en Gutiérrez, 2016), entrando en contradicción con otros agentes sociales y estatales, como el caso del denominado movimiento urbano popular.

Como ya se apuntó, este movimiento social urbano tuvo presencia en diversas ciudades de México, no solo en la Zona Metropolitana del Valle de México. Desde su origen en los años 60, fue una acción colectiva que encontró su génesis en tres causas principales: los procesos de urbanización popular, la forma clientelar y autoritaria que el Estado y el PRI -entre otros actores políticos- practicaban en las colonias populares para gestionar los procesos de urbanización y acceso al suelo, y finalmente, la acción de los agentes sociales en corrientes ideológicas de izquierda o "progresistas", como la "línea de masas" (Duhau y Coulomb en Gutiérrez, 2016).

Así, dentro del movimiento urbano popular se aglutinaron múltiples actores urbanos "grupos, organizaciones, coaliciones, frentes de colonos, de inquilinos, de solicitantes o cooperativistas, que reivindicaban condiciones necesarias para la reproducción de sus integrantes, como: tierra, vivienda, infraestructura y servicios urbanos" (Ramírez Saíz y Farrera en Gutiérrez, 2016). Estas agrupaciones, asociaciones, etcétera, han demandado la introducción y gestión de servicios urbanos en los asentamientos con un origen irregular o en colonias populares. Asimismo, sus demandas sociales y reivindicaciones trascienden para transitar hacia demandas y exigencias respecto al desarrollo de políticas urbanas para mejorar las condiciones de la precariedad urbana en la que viven, buscando una solución a la "irregularidad" e incertidumbre jurídica de los predios o lotes en los asentamientos irregulares (Gutiérrez, 2016).

Los procesos anteriormente mencionados por parte de los colonos populares de 
escasos recursos son esfuerzos por alcanzar y aprovechar todo lo que pueda ofrecer el medio urbano, con el propósito de alcanzar un pleno derecho a la ciudad en sus diversas escalas territoriales, como la vivienda, la calle, el barrio y la colonia.

\section{Procesos de urbanización popular en la Zona Metropolitana del Valle de México}

Como todo proceso, el de la urbanización es uno de los fenómenos sociales y territoriales más intensos y extensos del que se tenga cuenta. En su formación, desde la escala local la población se involucra de forma significativa en las formas de apropiación de los espacios y de la gestión urbana para el equipamiento, los usos de suelo y la vivienda, entre otros.

Entonces, se habla de una urbanización popular que desde múltiples variantes de intervención - principalmente en la escala local y municipal- en la producción y gestión de la ciudad, tiene como principal actor-constructor a amplios sectores de población de recursos escasos de las periferias o bordes urbanos. Así, se presenta el fenómeno como eso: como un proceso de urbanización popular.

En la investigación territorial de los procesos de la producción y expansión del espacio urbano, existe una línea de estudios que analiza la que es realizada por agentes sociales concretos, que tienen complejas relaciones con otros sectores y grupos de la sociedad, Estos agentes, en su acción articulada y conflictiva, son aquellos que al desplegar y realizar sus prácticas, materializan una forma de espacio urbano, siendo el resultado de sus acciones, imaginarios, representaciones y contradicciones, se convierte en una mediación para los propios agentes (Connolly, 2005 en Gutiérrez, 2016).

Asimismo, dichas investigaciones tienen en el centro del debate a los agentes sociales que construyen a la ciudad desde la base territorial de lo local y de la comunidad consideran sus prácticas y procesos de intervención urbana, con sus múltiples interacciones con actores sociales y políticos diversos como asesores, trabajadores sociales, arquitectos, organismos civiles, entre otros. La urbanización popular ${ }^{3}$ es una forma de producción del espacio urbano y habitacional, extendida de forma amplia en las ciudades de México y América Latina, proceso que puede ser identificado por tres características esenciales:

1) el acceso al suelo urbano de forma ilegal o irregular por parte de las familias de colonos urbanos y su asentamiento en zonas donde no existían usos de suelo urbano previo, 2) lugares donde la construcción de las viviendas y el proceso de urbanización es conducido y realizado por los propios habitantes, y 3 ) la precaria o nula disponibilidad de servicios públicos básicos y equipamiento urbano de uso colectivo en los nacientes asentamientos (Duhau, 1998; Schteingart y Duhau, 2002; Connolly, 2005 en Gutiérrez, 2016, pp. 7-8).

El acceso al suelo urbano (adquisición "legal" o "ilegal" de tierras), para la expansión urbana y habitacional, para el equipamiento urbano y la introducción de los servicios básicos, el mejoramiento urbano y de la vivienda, entre otros aspectos de las colonias populares, como procesos para la continua reproducción social de la población con recursos escasos.

En el caso de la urbanización popular en el oriente del Estado de México, Mora (2014, p. 25) advierte que: "los colonos se ven obligados a resolver las necesidades cotidianas e inmediatas de forma individual o grupal, sea en autoproducción o asistida por instituciones...", además señala: "...las formas de relación entre los pobladores y las instituciones se dan a través de mecanismos de gestión y autogestión...", y por último menciona:

...un mecanismo recurrente en tal proceso es el clientelismo (subrayado propio), que a pesar de no ser una relación legal tampoco puede definirse como ilegal, pues se maneja al margen de la ley, donde políticos y pobladores hacen acuerdos implícitos bajo las leyes de la palabra y la confianza (Mora, 2014, p. 25).

3. Supone otros procesos urbanos y sociales como la autoconstrucción y la autogestión. 
El mecanismo clientelar ha tenido el propósito de forjar posibles seguidores políticos - futuros votantes para la organización política, orientado de forma significativa hacia el clientelismo político para el Partido Revolucionario Institucional (PRI), practica muy recurrida por los agentes políticos, sobre todo en las décadas de los años 60 al 90. Después del triunfo de los partidos políticos con orientación de izquierda, se reprodujo el mismo fenómeno en la década del 2000, para el Partido de la Revolución Democrática (PRD).

Asimismo, Mora sugiere que:

Los actores de estas relaciones y gestiones son i) los pobladores, ...porque son los que habitan las colonias y son también el soporte social y ciudadano de los movimientos populares, ii) las instituciones, en ellas recae la acción de intervención para el mejoramiento de las colonias a través de programas de asistencia, y iii) los partidos políticos y los movimientos populares, suelen manejar representantes políticos para obtener legitimidad (Mora, 2014, pp. 25-26).

Asimismo, otros agentes muy importantes en el proceso de urbanización popular son los agentes privados que surgen de forma implícita, como los que ofrecen servicios diversos en torno a la propia formación de los asentamientos populares. Por ejemplo, los servicios de asesoría en trámites legales, asesorías en cuestión de arquitectura e ingeniería, entre otros aspectos, le imprimen un carácter mercantilista al propio proceso de la urbanización popular.

De acuerdo con la Figura 2, en la consolidación de las colonias populares - como lo menciona Mora (2014, p. 35)-, la interacción entre la gestión, autogestión y el clientelismo, son los procedimientos de gestión urbana que se advierten en el caso del oriente del Estado de México. Según Mora (2014) "... la gestión resuelve problemas puntuales a corto plazo, la autogestión ayuda a resolver equipamiento urbano que solo el gobierno puede proporcionar y el clientelismo es una combinación de ambas y es en tiempo electorales cuando tiene mayor eficacia." (Mora, 2014, p. 35).

Por su parte, Schteingart (1990, p. 2) entiende a la autogestión "como la forma de organización de las actividades sociales, tanto de tipo productivo, de servicios como administrativas, en las que las decisiones respecto de su conducción son tomadas directamente por los que participan en las mismas." Esta definición, es posible aplicarla a los términos autoorganización y autoconstrucción, porque da cuenta de actividades que realizan los propios pobladores sin la intervención o al margen del Estado.

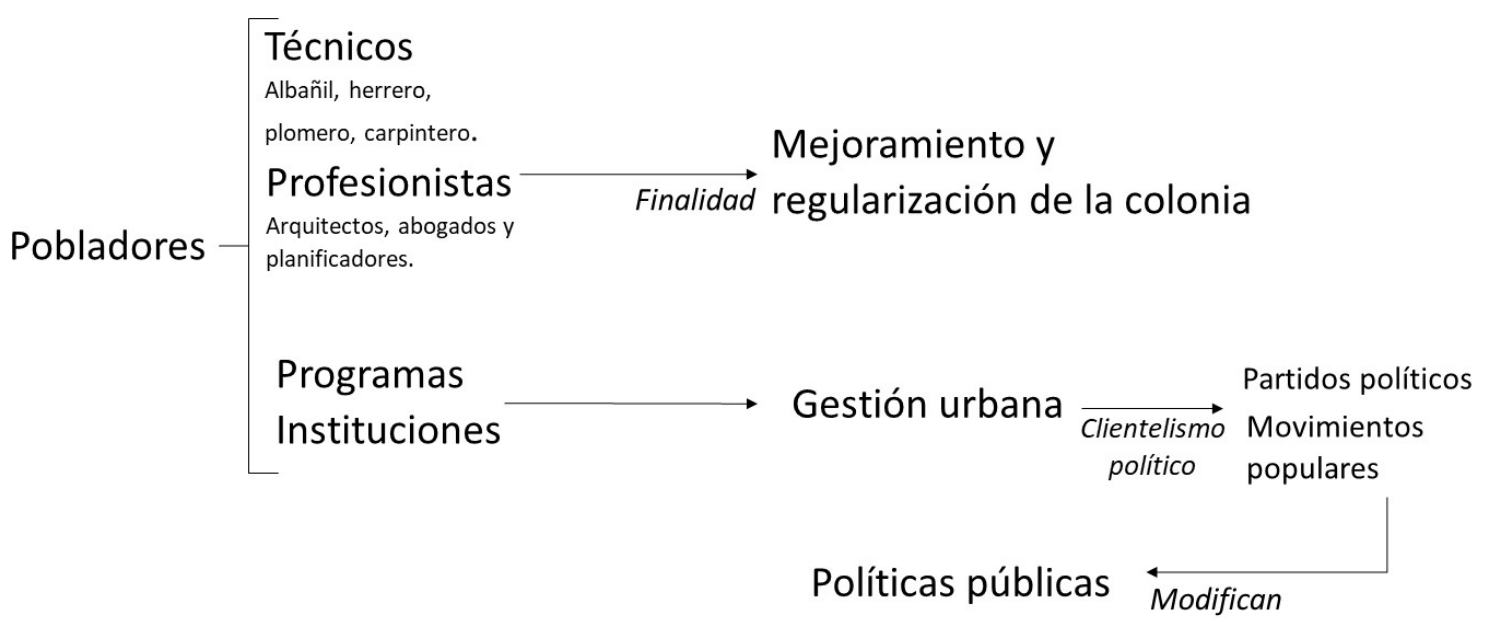

Figura 2. Sistema de gestión, autogestión y clientelismo en la urbanización popular, según Mora (2014). Fuente: Elaboración del autor, con base en Mora (2014, p. 35) 
Empero, han existido otras formas de apropiación y producción de la ciudad con otros actores sociales y con otras formas de apropiación del espacio urbano y del territorio, que se desarrollan en ambientes concretos, lejos de prácticas "politizadas" o con gestiones de tipo "clientelar" a un partido político, a un líder político, o a otras instituciones del Estado. En cambio, en otras experiencias de movimientos sociales populares, las instituciones participan, como gestores, facilitadores, asesores, etcétera, que son tareas que propiamente les competen, y teóricamente, sin ningún fin político o mercantil.

A continuación, se exponen dos casos puntuales de procesos urbanos populares que se han analizado para el oriente de la Zona Metropolitana del Valle de México y que es pertinente mostrarlos en este trabajo, para posteriormente contextualizar estos casos con el Derecho a la ciudad de la población popular por procesos de autogestión.

\section{La urbanización popular en el oriente del Estado de México: las catorce colonias.}

Con base en una investigación académica realizada por Mora (2014), que estudia la urbanización popular de catorce colonias ${ }^{4}$ ubicadas en los municipios de Los Reyes, Ixtapaluca y Chicoloapan en el oriente del Estado de México (lo que se considera como la periferia o el borde urbano del oriente de la Zona Metropolitana del Valle de México), se expone como los pobladores realizan sus prácticas territoriales en relación con la construcción social de su hábitat. El autor describe las características económicas y sociales de la zona de estudio y el proceso de urbanización popular con base en lo observado de forma personal, es decir, como observador participante en el sitio.

En primer lugar, Mora (2014) se percató de diversos problemas urbanos como la falta de energía eléctrica, drenaje y agua potable. Además de la inexistencia de equipamientos urbanos y sociales de atención a la población

4. Estas colonias o asentamientos humanos son los siguientes: Ampliación El Pino, El Pino, Tecomatlan, Villas San Isidro, Libertad, Casas Verdes, Mariel, Ex hacienda San Isidro, Ampliación Mariel, Primavera, 20 de Mayo, Lomas San Isidro y Lomas San Isidro I y II. local. Los colonos de las catorce colonias (consultar la Figura 3), se caracterizan por sus niveles de ingresos muy bajos, y es considerada como zona de marginación alta. Muchos de los trabajadores de las catorce colonias se desplazan hasta por 6 horas diarias - de ida y regreso- de su vivienda a los centros laborales.

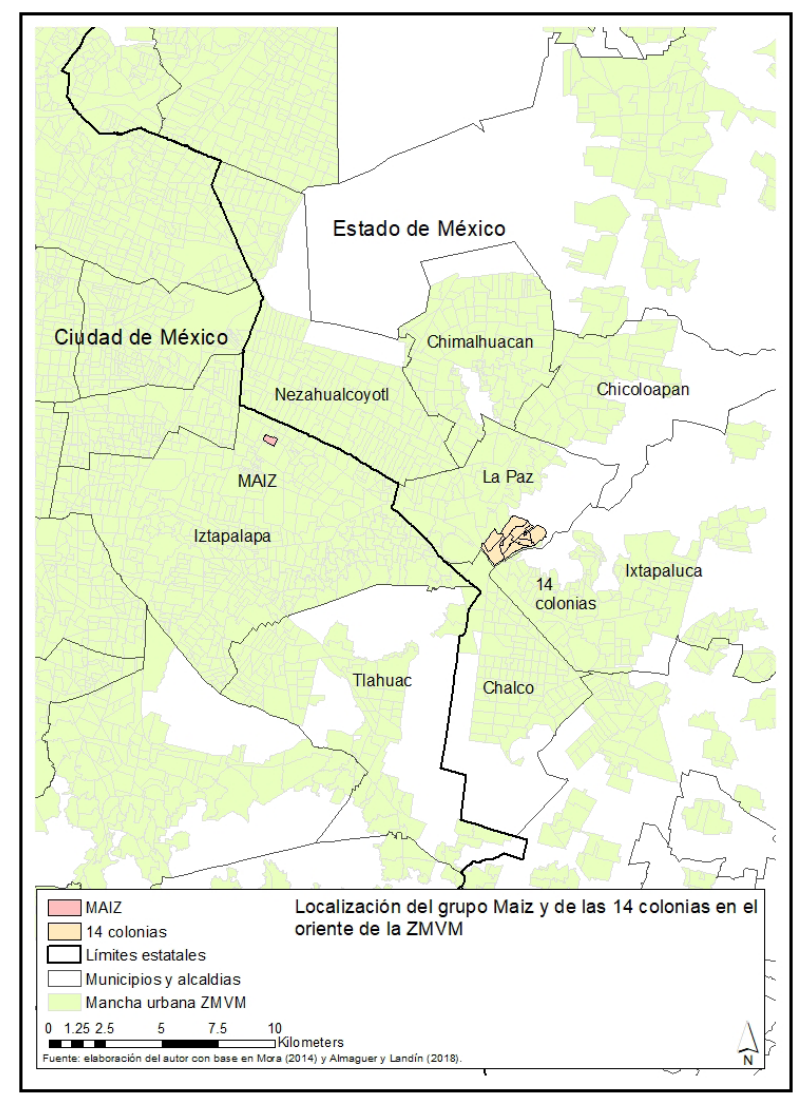

Figura 3. Localización de las organizaciones sociales de las 14 colonias y del grupo MAIZ en el oriente de la ZMVM. Fuente: elaboración del autor.

Los aspectos mencionados repercuten en la calidad de vida de los pobladores, y debido a estos componentes es que se indaga su relación con el tema del derecho a la ciudad que más adelante se trata. En segundo lugar, explica múltiples conflictos sociales en torno a la adquisición de suelo urbano, en la construcción de la vivienda y en etapas posteriores en la urbanización popular o en colonias en vías de consolidación urbana. 
Por último, advierte de los conflictos políticos y clientelares sujetos a una "promesa" - de los agentes políticos-, de tierra urbana o de una vivienda en tiempos electorales en el proceso urbano de la zona. Una organización que se destaca con las mencionadas prácticas es Antorcha Campesina ${ }^{5}$, caracterizada precisamente por el "clientelismo" político.

\section{Vivir en el borde urbano.}

El proceso de urbanización popular de las 14 colonias se ha caracterizado por:

...la gran necesidad de suelo para una vivienda, por familias de bajos recursos, los han llevado a invadir de forma ilegal terrenos privados, ejidales y de reserva natural, para construir ahí sus hogares. Las invasiones se dan casi siempre en la periferia de las ciudades, poco comunicadas, carentes de servicios, en zonas de alto riesgo y con condiciones ambientales adversas (Mora, 2014, p. 12).

Los agentes y aspectos que intervienen en este proceso, son: los pobladores, las instituciones, los partidos políticos y los movimientos populares y sociales (Mora, 2014, pp. 25-26). Como se puede ver en la Figura 2, mediante todo un sistema de gestión, autogestión y clientelismo en la urbanización popular, es cómo interactúan los actores y las formas de gestión urbana resultantes en el proceso de urbanización popular, con el propósito principal de lograr el mejoramiento social, económico y urbano de estas 14 colonias para conseguir la inclusión urbana y el derecho a la ciudad.

\section{La gestión urbana del grupo indígena MAIZ en la Alcaldía Iztapalapa, en el oriente de la Ciudad de México.}

En el segundo caso, con base en una metodología cualitativa, Espinosa (2018) documenta la experiencia de la Asociación Civil Movimiento de Artesanos Indígenas Zapatistas (MAIZ), organización popular que ha trazado su lucha urbana y construcción

5. Esta organización surge en el estado mexicano de Puebla la cual busca la lucha por la tierra y la disputa por mejores condiciones de desarrollo (Anzurez y Velázquez, 2013, p. 28). de su hábitat de forma comunitaria y por autogestión. MAIZ está conformado por indígenas mayoritariamente del grupo étnico triqui ${ }^{6}$ que se localiza en la Alcaldía de Iztapalapa, en la zona oriente de la Ciudad de México (Figura 3).

El trabajo de este grupo social está centrado en el análisis del proceso de configuración, gestión y producción de una unidad habitacional de 40 viviendas, financiadas por el Instituto de Vivienda de la Ciudad de México (INVI) y la Comisión Nacional para el Desarrollo de los Pueblos Indígenas (CDI).

Espinosa (2018) comenta que la particularidad de esta experiencia:

...radica en la concepción integral de vivienda promovida por esta organización, en donde se contempla la casa-habitación como un espacio integrado al conjunto habitacional, configurado este último por una serie de espacios emanados de la participación colectiva y de diferentes prácticas donde se llevan a cabo procesos de socialización, que posibilitan la reconfiguración de los elementos étnicos desde diferentes esferas de la vida cotidiana. (Espinosa, 2018, p. 13)

Desde el ámbito de la gestión urbana, uno de los aspectos que permite la identificación de los escenarios de negociación y confrontación es el manejo del tiempo de los procesos, tanto el establecido por los marcos normativos institucionales, como el que lleva a cabo el actor social que aspira a acceder al programa gubernamental, en este caso de vivienda popular.

Los mecanismos de gestión institucional a partir de los marcos normativos del Instituto de Vivienda de la Ciudad de México que es el agente gubernamental con esa encomienda-, se encuentran en relación con el proceso de administración para la obtención de créditos por parte del grupo MAIZ a través del Programa de Mejoramiento

6. Grupo indígena originario del estado mexicano de Oaxaca, parte de su población emigra de sus localidades de origen hacia la Ciudad de México. 
de Vivienda (PMV), lo que determina los referentes espaciales-urbanos y las dinámicas emanadas a través de pautas e intervalos concretos de acción.

Algunas consideraciones de la asociación MAIZ, son que el grupo indígena triqui en una trayectoria de más de 15 años, han logrado reconstruir su identidad étnica en un ambiente urbano popular, en donde continua el estigma social hacia el indígena y ante la ausencia de políticas públicas que traten su incorporación plena (Espinosa, 2018). De acuerdo a sus usos y costumbres, han adquirido tramites ajenos a su cultura; empero, continúan conservando otras formas de organización social y comunitarias ancestrales.

Por ejemplo, se constituyeron en una asociación civil en una mesa directiva, logrando así, "la refuncionalización de sus estructuras tradicionales en torno a líderes comunitarios y retomaron la asamblea comunitaria como espacio para la toma de decisiones" (Espinosa, 2018, p. 16). Aunque el grupo MAIZ ha tenido apertura a otro tipo de agentes sociales, en la cual existe la "confrontación" con las estructuras institucionales (u "oficiales", subrayado propio) al carecer de programas integrales que garanticen su desarrollo (Espinosa, 2018, p. 17).

Las demandas urbanas como las de equipamiento urbano, servicios básicos y de vivienda, entre otras, "se ven obstruidas por la falta de sensibilidad de funcionarios públicos, que se rigen por una interpretación rígida de los marcos normativos que orientan su función" (Espinosa, 2018, p. 17). Son dos tiempos enfrentados: el tiempo institucional y el tiempo social y comunitario, como en el caso de los procesos de gestión urbana del grupo MAIZ. (Espinosa, 2018, p. 18). De este modo, el autor plantea que son seis etapas y en cada una se presentan los escenarios siguientes:

En las alianzas y conflictos del grupo MAIZ, se muestran una serie de relaciones tales como: la confrontación con las instituciones, el deterioro de las relaciones sociales, una red de subsistencia entre actores indígenas, la reconstitución de los lazos étnicos y acercamiento ( $y$ distanciamiento en ciertos momentos), con los actores institucionales y sociales (Espinosa, 2018).

Otras características que advierte Espinosa (2018) en los momentos indicados, son: policronía temporal para la subsistencia, territorialidad en pugna como el despojo territorial, la dispersión social, ausencia de territorio, acercamiento al tiempo monocrónico institucional, flexibilidad del referente étnico, dominio de los tiempos rituales y comunitarios, entre otros aspectos, como las mostradas en la tabla 1, que sintetizan las relaciones y características de cada una de las etapas que constituyen la trayectoria del grupo indígena triqui MAIZ.

Tabla 1. Etapas y escenarios del grupo MAIZ

\begin{tabular}{l}
\hline 1. La expulsión del lugar de origen. \\
\hline 2. El arribo a la Ciudad de México. \\
\hline 3. La conformación del grupo y gestión del proyecto. \\
\hline 4. El proceso de autoproducción de la vivienda triqui. \\
\hline $\begin{array}{l}\text { 5. La apropiación del espacio y búsqueda del espacio } \\
\text { de comercialización. }\end{array}$ \\
\hline $\begin{array}{l}\text { 6. El nuevo proyecto de vivienda y los dilemas del } \\
\text { proyecto colectivo. }\end{array}$ \\
Fuente: Elaboración del autor, con base en información \\
de Espinosa (2018, p. 19).
\end{tabular}

Espinosa (2018), menciona que la organización MAIZ no ha logrado consolidar un proyecto político que se articule con otros procesos de lucha de actores sociales afines a su posición, por ejemplo, los grupos de inmigrantes rurales o urbanos que se organizan para acceder a suelo y vivienda en la Ciudad de México. En el grupo MAIZ hay enfrentamientos y conflictos internos, como el cambio generacional de sus integrantes, la perdida de costumbres, emanados del cambio generacional y de estrategias diferenciadas de la gestión y construcción del proceso identitario (Espinosa, 2018).

Entonces, el componente antropológico temporal es determinante en la lucha urbana por el acceso y apropiación de la ciudad. 
No solo por los trámites institucionales, sino también por las practicas indígenas de usos y costumbres y su adaptación a las practicas urbanas corporativas, ambas destemporalizadas. Sin embargo, el grupo MAIZ ha logrado gestionar su entorno urbano popular para solventar sus proyectos urbanos, habitacionales y sociales.

De esta manera, son dos las formas temporales enfrentadas en la gestión urbana: El tiempo policrónico, del actor social; es decir, los tiempos simultáneos que maneja el grupo MAIZ como su cosmogonía, usos y costumbres; y el tiempo métrico institucional, del actor institucional, el de las autoridades de la Alcaldía. En última instancia, los actores urbanos como la organización MAIZ y los grupos de colonos urbanos en el caso de las catorce colonias, se enfrentan a procesos urbanos similares en su inclusión a la oferta de la ciudad, en donde la demanda urbana la supera.

En el caso del proyecto de vivienda para el MAIZ, las etapas de planeación (ver Figura 4) son la gestión, el proyecto, la construcción y la apropiación (Espinosa, 2018).

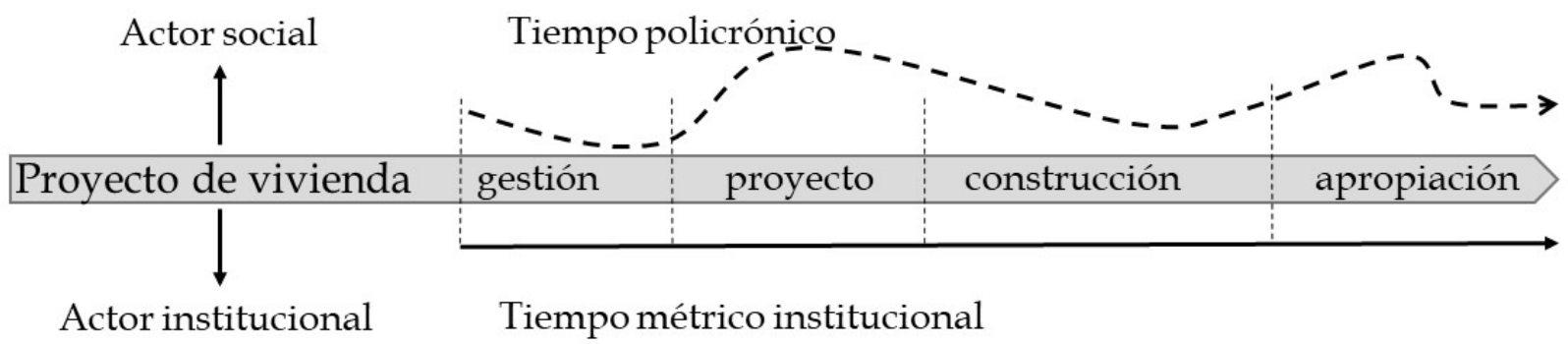

Figura 4. Esquema del tiempo en el proceso de gestión, producción y apropiación Fuente: Elaboración del autor, con base en una Figura de Espinosa (2018: 19).

Finalmente, los dilemas que enfrenta el grupo étnico MAIZ giran en torno a varias contradicciones de organización y de estrategias propias, que tendrán que dirimirse al interior del propio grupo y en el escenario de las confrontaciones con los actores institucionales (Espinosa, 2018). Son formas de adaptación al entorno urbano en ambientes desfavorables, como las relaciones sociales e institucionales con los actores urbanos gubernamentales.

Como menciona Espinosa (2018, p. 18), "...significan algo más que un asunto de adaptabilidad al escenario urbano, al colocar en la agenda pública los dilemas de la inclusión y de la diversidad urbana". Asimismo, como parte de la cosmovisión propia y de prácticas sociales propias, dan significado al lugar geográfico y temporal que ocupan como grupo indígena en el actual proceso de urbanización popular y de sus posibilidades de apropiación del espacio urbano; es decir, se encuentran en una búsqueda de alcanzar el derecho a la ciudad.

\section{El Derecho a la Ciudad.}

En el concepto del derecho a la ciudad de Lefebvre, éste advirtió la cada vez mayor especulación del capital, la exclusión y la pobreza de las clases proletarias urbanas. Por ello, propuso un modelo en el que la ciudad es un espacio que se imagina y se construye mediante la intervención directa de sus habitantes. Además, señalaba que el derecho a la ciudad y a la vida urbana eran una condición básica de un humanismo y de una democracia renovada.

Se trataba del derecho al uso intenso de una ciudad y al uso pleno de sus lugares de encuentro y de intercambio social y cultural, producto de la gran revolución que la "sociedad urbana" realizaría (Lefebvre en Delgadillo, 2012).

Con base en el planteamiento de Lefebvre, David Harvey (2013) asume el derecho a la ciudad expresado por los movimientos anticapitalistas urbanos, como la posibilidad 
de transformar y recuperar la ciudad como bien común. Sin embargo, a diferencia de Lefebvre, Harvey postula que las "ciudadanías insurgentes", y no la lucha obrera, son la forma y el vehículo que pueden materializar las utopías por hacer del territorio un escenario de construcción de alternativas espaciales en diversas escalas, que van de lo personal a lo regional, y que pueden contribuir a restringir los efectos urbanos de la apropiación capitalista del espacio (Harvey, 2013; Molano, 2016).

Con base en lo planteado por Molano (2016), Harvey asume el derecho a la ciudad mediante dos componentes de su modelo explicativo, a saber: la producción social del espacio y de la ciudad, por parte del capital, y las posibilidades políticas y sociales de ejercer el derecho a la ciudad, un derecho cada vez más negado para amplios sectores de la población (Molano, 2016).

Si es una lucha de los sectores populares, entonces el acceso a la ciudad en su conjunto, en las condiciones económicas desfavorables para las poblaciones marginadas de la urbe, se contradicen y profundizan en la actual fase neoliberal del capitalismo. Sin embargo, surgen varias interrogantes sobre ese derecho a la ciudad.

En relación a ello, algunas preguntas que se cuestiona Delgadillo (2012) son: ¿Es posible la realización del derecho a la ciudad en la era neoliberal? ¿Es posible garantizar el uso equitativo de la ciudad, cuando este territorio, integrado por propiedades privadas, ha sido producido por un mercado inmobiliario que se rige por la maximización del lucro? Al respecto, responde el mismo autor que:

...una ciudad cuyo gobierno, por un lado, ha asumido este derecho en la esfera de los "compromisos políticos" al suscribir "La Carta de la Ciudad de México por el Derecho a la Ciudad", y por otro lado, se empeña en la realización de megaproyectos que directamente favorecen los negocios privados, generan oposición social y contribuyen a dividir la ciudad, en una exclusiva para ricos y otra excluida para pobres, como es en el caso de las vialidades elevadas y confinadas de cobro concesionadas al sector privado. (Delgadillo, 2012, p. 118).

En relación con el documento "Carta de la Ciudad de México por el Derecho a la Ciudad" (2011), establece en el capítulo primero la definición del Derecho a la Ciudad, el cual es:

El Derecho a la Ciudad es el usufructo equitativo de las ciudades dentro de los principios de sustentabilidad, democracia, equidad y justicia social. Es un derecho colectivo de los habitantes de las ciudades, que les confiere legitimidad de acción y de organización, basado en el respeto a sus diferencias, expresiones y prácticas culturales, con el objetivo de alcanzar el pleno ejercicio del derecho a la libre autodeterminación y a un nivel de vida adecuado (Carta de la Ciudad de México por el Derecho a la Ciudad, 2011, p. 15).

\section{RESULTADOS}

El proceso de urbanización popular lo realiza, conduce y gestiona la propia población que vive en las periferias urbanas, con ayuda y asesoría de arquitectos, planificadores, abogados, actores políticos y agentes de los gobiernos municipales y estatales. También, en tiempos políticos de elecciones para ocupar cargos de gobierno y diputaciones, algunos programas de asistencia gubernamental entran en las comunidades urbanas y resuelven reclamos sociales para el mejoramiento urbano y de suelo urbano con el propósito de urbanizarse.

En el caso del oriente de la Zona Metropolitana del Valle de México, el trabajo popular emprendido por diversas organizaciones sociales de colonos urbanos y grupos indígenas, entre otros, tiene como rasgos principales los objetivos siguientes: participar, construir, diseñar y recuperar la ciudad en la que viven, desde la vivienda, la calle, el barrio y la propia colonia popular, como componentes constantes 
en la autoorganización, autogestión y autoconstrucción popular. Este es el caso, del grupo indígena triqui MAIZ y de los pobladores urbanos de las 14 colonias y de otras organizaciones sociales y populares relacionadas al Movimiento Urbano Popular.

Históricamente, las luchas urbanas populares han sido el eje de los espacios y de territorios urbanos ocupados, reocupados, recuperados o de reciente creación y apropiación independiente, sin intervención - aparentede los actores institucionales "oficiales" y con una actuación significativa por parte de los actores locales. Lo anterior, ha sido parte de las luchas urbanas populares para un uso equitativo de la ciudad como un derecho al que tiene la población popular.

El ideal del derecho a la ciudad propone, en principio, eliminar las desigualdades sociales de la población de escasos recursos. Asimismo, plantea minimizar las desventajas territoriales por la localización geográfica de las zonas habitacionales populares, a las cuales le distinguen los siguientes rasgos: 1. Los asentamientos populares tienen ineficientes servicios básicos urbanos y sociales y 2 . La población popular se localiza alejada de las actividades económicas y sociales esenciales, por ejemplo, de los centros laborales, sociales, culturales etc., lo que provoca una movilidad laboral precaria con trayectos extensos en tiempo y distancia entre los orígenes y los destinos.

Lo anterior, es una cuestión de justicia urbana, o como menciona Jordi Borja: "La 'injusticia espacial' es el lugar donde se niega la inclusión y la apropiación del territorio, es la negación de los atributos de la ciudadanía." (Borja en Sánchez, 2020).

\section{DISCUSIÓN}

Es el Estado, con sus diversas instituciones, planes y programas, el encargado de proveer de los servicios básicos en las comunidades urbanas con población de escasos recursos. Así, el gobierno con sus acciones sociales, cumple un papel exclusivamente administrativo, es decir de gestión básica $y$, si acaso, de facilitador administrativo.
Empero, son los propios habitantes de las comunidades rurales y urbanas, quienes, mediante diversas exigencias y estrategias urbanas y sociales, Reivindican su derecho a la ciudad, como lo establecieron Lefebvre y posteriormente Harvey.

Un reclamo vigente y continuo en los procesos de urbanización popular, bajo la premisa de tomar en cuenta las necesidades vitales de la población popular. Es decir, la construcción de la ciudad realizada por la población popular ante la ineficacia gubernamental y la desatención social del Estado en tiempos de neoliberalismo.

En América Latina, los territorios como lugares sociales para el usufructo de la población urbana se encuentran, en su mayor parte, en posesión de los agentes económicos privados. Como ejemplo, son los espacios urbanos públicos y las áreas naturales en la ciudad que han sido tomadas por empresas privadas urbanas, como los desarrolladores inmobiliarios, empresas de espectáculos y de la construcción, solapados - apoyados por actores gubernamentales que se apropian del espacio público urbano, y de esta forma excluyen y segregan a amplios sectores de la sociedad.

Ante ese aspecto adverso para las comunidades, la respuesta es la organización urbana popular en relación a los procesos urbanos en un contexto de privatización y mercantilización de la ciudad.

Como lo menciona Pírez (2013), en la urbanización popular una constante es la precarización de la vida de sus pobladores; en la cual, los habitantes marginados crean, recrean, construyen e imaginan posibilidades de una vida mejor en todos los aspectos. Entonces el imaginario social es fuente de dicha posibilidad, como en el caso del grupo indígena triqui MAIZ.

Entonces, la organización, la gestión y la construcción de la ciudad, se caracterizan por la participación de los pobladores al legitimar la vivienda, el entorno urbano, la calle y el barrio. Es una forma de producción de la ciudad en la que la población popular es el principal actor que la construye. En esta 
perspectiva, el derecho a la ciudad se sitúa principalmente en el contexto local de las colonias populares. ¿Será entonces también un autoderecho a la ciudad?

Con base en la concepción de Schteingart (1990), autogestión es una forma de organización social de corte administrativo y productivo en la que la conducción la toman directamente los pobladores. De esta forma, en el derecho urbano popular son los propios habitantes interesados quienes logran acceder a lo que les puede ofrecer la ciudad, pero alcanzado y diseñado de forma propia, es decir, el mismo derecho que el Estado no les ha procurado.

Ante las actuales condiciones sociales y económicas, como el neoliberalismo, la globalización y el diseño urbano inequitativo, es tiempo que la arquitectura y el urbanismo procuren la inclusión urbana y la integración plena de los habitantes a la ciudad. Como disciplinas del diseño deben ofrecer la posibilidad para que los habitantes cuenten con diseños incluyentes, equilibrados y armónicos. Es necesario, entonces, quitar el velo de la mercantilización en las formas urbanas para mejorar las condiciones sociales y urbanas de quienes habitan la ciudad.

También, cabe mencionar las limitantes urbanas a los pobladores populares de escasos recursos en el conjunto de la ciudad, que hablan de todo lo contrario a un uso equitativo de la ciudad sustentable y democrática, como se establece en la "Carta de la Ciudad de México por el Derecho a la Ciudad" (2011). La inclusión urbana de la población con recursos escasos, como colonos, grupos indígenas, inmigrantes, entre otros, ha sido posible desde la participación ciudadana de estos grupos sociales

Entretanto, se construyen versiones distintas de ciudad: la popular, la de clase media, la inmobiliaria, la financiera, la de megaproyectos, la de puentes viales, la de automóviles, entre muchas otras. Una propuesta en este trabajo es abrir el debate y la investigación urbana hacia esas otras formas de hacer ciudad, y del derecho a habitarla y vivirla por parte del conjunto de sus habitantes.

Habría que investigar también lo opuesto a la urbanización popular de la ciudad, como el desarrollo inmobiliario y residencial, y el urbanismo que se hace desde los actores privados e institucionales del Estado, para conocer más a fondo la contraparte de este proceso. De esta forma, podríamos contar con más elementos teóricos y metodológicos que expliquen esas realidades opuestas y comprender sus procesos, dinámicas, semejanzas y diferencias.

Para el oriente de la Zona Metropolitana del Valle de México, propongo continuar con la investigación sobre los vínculos urbanos o metropolitanos que mantienen las alcaldías de Tláhuac, Iztapalapa e Iztacalco (Ciudad de México), con los municipios de Nezahualcóyotl, Los Reyes, La Paz e Ixtapaluca (Estado de México), los cuáles presentan unos procesos urbanos muy particulares con presencia de grupos multiculturales, populares, indígenas, entre otros. Grupos en busca de un usufructo pleno de la Ciudad y de la metrópoli.

Finalmente, planteo una reflexión incesante sobre el poder de cambio de la realidad social de la población marginada, popular, periférica o de escasos recursos; porque en tiempos de una globalización neoliberal imparable, estas comunidades urbanas buscan una de las necesidades humanas primordiales: elevar las condiciones en la calidad de vida de la población con recursos escasos. Esta es la protagonista en el proceso de urbanización popular, la cual requiere de una planeación urbana incluyente para sus territorios con procesos urbanos sui generis, como los que están presentes en el oriente de la Zona Metropolitana del Valle de México. 


\section{REFERENCIAS}

Almaguer, M. y Landin, J. M. (2018) Cómo mejorar la movilidad en el oriente de la Ciudad de México. Revista electrónica Nexos, Sección "La brújula", agosto 28, 2018. Disponible en https://labrujula.nexos.com.mx/?p=2041

Anzurez, H. J. y Velázquez, E. J. (2013) Desarrollo político de Antorcha Campesina: de organización social a partido político. Tesis de licenciatura, FES Aragón, UNAM. México. http://132.248.9.195/ptd2013/enero/0688663/Index.html

Carta de la Ciudad de México por el Derecho a la Ciudad (2011). Gobierno del Distrito Federal. Disponible en: https://hic-al.org/wp-content/uploads/2019/02/CARTA CIUDAD 2011muestra.pdf

Comisión Económica Para América Latina y el Caribe - CEPAL (2018). Balance Preliminar de las Economías de América Latina y el Caribe 2017. Santiago de Chile: CEPAL. Disponible en: https://repositorio.cepal.org/bitstream/handle/11362/44326/141/S1801219 es.pdf

Delgadillo, V. (2012) El derecho a la ciudad en la Ciudad de México. ¿Una retórica progresista para una gestión urbana neoliberal? Andamios, 9(18), 117-139. Disponible en: https:// www. redalyc.org/articulo.oa?id $=62823326006$

Duhau E. (2000). Hábitat popular y política urbana. Sociológica, 15(42),269-273.

Disponible en: https://www.redalyc.org/articulo.oa?id=3050/305026734008

Espinosa, F. A. (2018). La disputa del tiempo en los procesos de gestión urbana. Revista Diseño y Sociedad Núm. 45. CyAD, Universidad Autónoma Metropolitana, Xochimilco. Disponible en: https://publicaciones.xoc.uam.mx/TablaContenidoFasciculo.php?id fasciculo=844

Gutiérrez, G.G. (2016) El movimiento urbano popular en el D.F. (1968-1991): urbanización popular y sociedad civil en la producción del espacio urbano. Universidad Nacional Autónoma de México. Facultad de Filosofía y Letras. Disponible en: https:// tesiunam.dgb.unam.mx/F/23CNTJYJX59VQICSYQUDG4M83IJ88VTEGJJKJTVDFNV6UMXE $\underline{Y G-00386 \text { ? func }=\text { full-set-set\&set number }=432187 \& \text { set entry }=000002 \& \text { format }=999}$

Harvey, D. (2013). Ciudades rebeldes. Del derecho a la ciudad a la revolución urbana. Madrid: Akal. Disponible en: https://cronicon.net/paginas/Documentos/CIUDADES REBELDES. pdf

Instituto Nacional de Estadística, Geografía e Informática - INEGI (2017) Encuesta Origen - Destino, 2017. México, Instituto Nacional de Estadística, Geografía e Informática. Disponible en: http://giitral.iingen.unam.mx/Estudios/EstudioOD-ZMVM-2017.html

Lefebvre, H. (1975). El derecho a la ciudad. 3.a ed. Barcelona: Península. Disponible en: https://www.comunicacionyrurbanidad.org/wp-content/uploads/2018/03/Lefebvre-Elderecho-a-la-ciudad3.pdf

Molano, F. (2016) El derecho a la ciudad: de Henri Lefebvre a los análisis sobre la ciudad capitalista contemporánea. Revista Folios, (44),3-19. Disponible en: http://www.scielo. org.co/pdf/folios/n44/n44a01.pdf 
Schteingart, M. (1990) Aspectos teóricos y prácticos de la autogestión urbana. Sociológica. Revista del Departamento de Sociología. UAM, Azcapotzalco. México. Disponible en: http://www.sociologicamexico.azc.uam.mx/index.php/Sociologica/article/view/944/916

Mendoza, A. (2016). Procesos y lógicas de las urbanizaciones cerradas en áreas metropolitanas: Bogotá, Colombia y Buenos Aires, Argentina. Procesos Urbanos, 3(3), 55 - 78. https:// doi.org/10.21892/2422085X.267

Mora, D. (2014) La urbanización popular en el oriente del Estado de México. División de Ciencias y Artes para el Diseño. Tesis de Doctorado. UAM-X. Disponible en: http://2wcavi. com/docs/urbanizacion\%20popular.pdf

Palmett, O. (2016). Externalidades ambientales ocasionadas por la urbanización en la ciudad de Medellín. Procesos Urbanos, 3(3),38-54. https://doi.org/10.21892/2422085X.266

Pírez, P. (2013) La urbanización y la política de los servicios urbanos en América Latina. Andamios, 10(22),45-67. Disponible en: https://www.redalyc.org/pdf/628/62828837003.pdf

Quiroz, H. y Alcántar, E. (2017) El urbanismo popular en México. Elementos para una historia pendiente. Urbana: Rev. Eletrônica Cent. Interdiscip. Estud. Cid Campinas (SP) v.9, n.1 [15] p.47-69 ISSN 1982-0569. Disponible en: https://periodicos.sbu.unicamp.br/ojs/ index.php/urbana/article/view/8647221

Sánchez, R. (2020) El derecho a la ciudad. Letra S. Suplemento de La Jornada. Disponible en: http://letraese.jornada.com.mx/2018/01/31/el-derecho-a-la-ciudad-4890.html 